\title{
Navigation within host tissues: cues for orientation of Diplostomum spathaceum (Trematoda) in fish towards veins, head and eye
}

\author{
W. HAAS*, C. WULFF, K. GRABE, V. MEYER and S. HAEBERLEIN \\ Institute for Zoology I, University Erlangen-Nuernberg, Staudtstrasse 5, D-91058 Erlangen, Germany
}

(Received 10 November 2006; revised 22 December and 28 December 2006; accepted 5 Fanuary 2007; first published online 22 February 2007)

\begin{abstract}
S U MMARY
Cercariae of Diplostomum spathaceum penetrate the skin of fish, and then migrate along blood vessels and tissues towards the head and the eye-lens. We studied their orientation behaviour in tail fins of guppies and in chemical concentration gradients within agar-filled choice chambers. In fins, they entered veins and orientated cranially, independent of the blood flow and living cells. In choice chambers, they were attracted by a small molecular fraction of fish serum, D-glucose (at 1, 10, and $1000 \mu \mathrm{M}$ ), D-mannose, D-maltotriose and Cl-ions, whereas D-glucosamine repelled them (even at 1.0 nM). Amino acids were not attractive, but arginine in tetrapeptides attracted at concentrations as low as $1 \mu \mathrm{M}$ and melatonin at $0 \cdot 4-4 \cdot 3 \mathrm{pm}$. We suggest a preliminary model for the behaviour of diplostomula in fish fins and attracting $(+)$ or repelling $(-)$ host cues: $(1)$ migration towards deeper skin layers and avoidance of skin surface, cues: Cl-ions (+ and -$)$, glucose $(+)$, glucosamine $(-)$, light radiation $(-)$; (2) orientation in cranial direction, cue: Cl-ions $(+) ;(3)$ localization of blood vessels, cues : glucose $(+)$, arginine-residues $(+)$; (4) localization of the retina, cue: melatonin $(+)$. A comparison with the navigation mechanisms of tissue-migrating schistosomules and hookworm larvae reveals an enormous diversity of strategies.
\end{abstract}

Key words: Diplostomum spathaceum, cercaria, diplostomulum, chemotaxis, orientation mechanisms, parasite behaviour, site-finding, fish parasite.

\section{INTRODUCTION}

Many parasites migrate in their hosts towards very distinct habitats. The complex, well-defined paths of migration to the final locations within hosts have been described for many parasites, but little is known about how organisms navigate and locate their destinations within hosts (reviewed by Sukhdeo and Sukhdeo, 1994, 2002, 2004). We studied the orientation of infective larvae of skin-invading parasitic worms after their penetration into agar substrates (Haas et al. $2002 a$, 2005; Grabe and Haas, $2004 a, b)$. The schistosomula of the human parasite Schistosoma mansoni and the duck parasite and agent of human cercarial dermatitis, Trichobilharzia ocellata, were attracted by sera of their hosts with arginine and glucose as the guiding compounds. We hypothesized that these 2 cues were used by the migrating parasites (1) to orientate towards deeper skin layers, (2) to determine their position during their surface-parallel migration within the epidermis and (3) to locate blood vessels. Arginine and glucose seem to be suitable host signals for these invasion phases, and the question arises whether this navigation strategy may generally be used by

* Corresponding author: Tel: +4991318528064. Fax: + 4991318528040 . E-mail: whaas@biologie.unierlangen.de digeneans that penetrate skin and seek blood vessels for further migration. Therefore, we studied this topic with Diplostomum spathaceum (syn.: Diplostomum pseudospathaceum, as described by Niewiadomska (1984) and Niewiadomska and Kiseliene (1994)), whose cercariae penetrate fish hosts and migrate towards their eye-lenses. The D. spathaceum - fish host model has the advantages that fish as hosts are more suitable for in vivo experiments than mammals and birds and that much is known about cercarial behaviour and the migration of the parasite within the host.

The cercariae of D. spathaceum attach to a broad spectrum of aquatic animals in response to water currents, touch, and carbon dioxide (Haas, 1974a, $b$, 1975), but they remain only on mucus-covered animals in response to small molecular weight carbohydrates. Then, they penetrate their hosts, stimulated by glycoproteins with sialic acids as signalling residues and defined free fatty acids (Haas et al. 2002b). After penetration, the diplostomula migrate towards the head, enter the eyes and then the lenses for further development. Studies on the migratory routes revealed inconsistent results. Histological techniques showed most migrating diplostomula in connective and muscle tissues and, as only few were located in the circulatory system, it was argued that the blood system does not serve as a major migratory route (Erasmus, 1959; 
Ratanarat-Brockelman, 1974). However, observations in living fish and amphibia and experimental in vivo approaches suggested that diplostomula migrate mainly along blood vessels (Davis, 1936; Ferguson, 1943; Betterton, 1974; White et al. 1991). Our unpublished observations of diplostomula in fins and tails of guppies and in bodies of the translucent species Chanda ranga and Kryptopterus bicirrhis support the view that blood vessels are important migration routes. It can easily be observed that the parasites enter blood vessels and migrate rapidly within the lumen. But normally they also leave the vessels and burrow their way in a cranial direction in tissues, until they eventually enter blood vessels again. Therefore, most diplostomula are seen digging in tissues, but the few creeping in the vessels cover the main distances. Therefore, we suppose that D. spathaceum is adapted to the location of blood vessels like $S$. mansoni and T. ocellata. We consider it as a suitable model for analysis of navigation mechanisms, particularly for comparison with what we already know on the navigation strategies of schistosomes.

\section{MATERIALS AND METHODS}

\section{Experimental conditions}

Cercariae of D. spathaceum were obtained from naturally infected Lymnaea stagnalis snails using methods described by Haas et al. (2002b). Penetration of cercariae into tail fins and their migration within the fins of female guppy (Poecilia reticulata) was observed with dissecting microscopes and their path of migration was drawn using a camera lucida. Living guppies were fixed with rubber bands in an infection compartment of a Petri dish. The fish were provided with aerated water, free of cercariae, by separating the head and the gills from the infection chamber with a plastic membrane. Groups of 50-200 cercariae were introduced into the infection chamber and the behaviour of individual cercariae recorded.

The in vitro chemo-orientation of the diplostomula was studied with a 2-choice experimental chamber modified after the $\mathrm{W}$-chamber method as described by Haas et al. (2002a) and Grabe and Haas (2004a). Briefly, the larvae penetrated agar in the central chamber $(5 \times 5 \mathrm{~mm}$, height of agar $6 \mathrm{~mm})$ of a 3 -armed cuvet. In typical experiments, the agar $(0 \cdot 5 \%$; pH $7 \cdot 0,5$ mu sodium phosphate buffer $)$, as well as the test and control substrates contained Ringer solution (composition, see Table 2) or defined salt solutions. Penetration and full transformation into diplostomula (as indicated by lectin staining; see Haas et al. 2002a) was stimulated by a $1-$ mm layer of agar, containing linolenic acid, on the upper surface of the central agar block $(0.05 \mathrm{~mm}$ linolenic acid in $0 \cdot 5 \%$ agar, $\mathrm{pH} 7 \cdot 0,5 \mathrm{~mm}$ sodium phosphate buffer).
The central agar block of the chamber was connected with lateral blocks of similarly composed agar, supplemented with test or control substrates, respectively. After placing $70-150$ cercariae in $70 \mu \mathrm{l}$ of water on the central agar blocks (constant numbers per experimental series), the chambers were incubated for $120 \mathrm{~min}$ at $22^{\circ} \mathrm{C}$ in darkness and the number of diplostomula in the agar of the central arm and in the test and control agar was recorded. In experiments with macromolecules (Table $2 \mathrm{~A}, \mathrm{C}, \mathrm{D}, \mathrm{E}$ ), the test and control substrates were integrated in the lateral agar blocks and in experiments with small molecular weight compounds the substrates were applied within buffered Ringer or salt solution ( $\mathrm{pH} 7 \cdot 0,5 \mathrm{~mm}$ phosphate buffer) on the lateral agar blocks. Concentration gradients of the substrates became established by diffusion across the agar blocks as determined by the diffusion rate of chemicals within the system (Grabe and Haas, 2004a).

The sensitivity of different cercarial populations (even from the same individual snails) to penetration and orientation stimuli varies from day to day and furthermore depends on the age of the parasites. Therefore, these experiments used cercariae within $3 \mathrm{~h}$ after being shed, and all quantitative comparisons were done using the same cercarial populations from 4-15 individual host snails. All results in Table 2 were confirmed by additional experimental series (data not shown).

Chemo-orientation of diplostomula in the $\mathrm{W}$-chambers was evaluated by comparing the numbers of diplostomula leaving the central arm of the chambers in direction to test- and control substrates. More diplostomula left the central arm when there was an attractant in the chamber than in control experiments, but this did not affect the statistical analysis. In Table 2 only the numbers of diplostomula showing orientation (i.e. leaving the central arms) was shown, the numbers of the cercariae penetrating the substrates and the percentage of these showing orientation was omitted for clarity. All in vitro experiments used a blind protocol; the test substrates were given a code unknown to the experimenters.

The effect of melatonin on the photo-orientation of migrating diplostomula was studied with methods modified from Grabe and Haas (2004b). Briefly, the agar of the $\mathrm{W}$-chambers contained melatonin in Ringer or Ringer only, and the chambers were illuminated from one side with cold light sources or neon lamps through heat filters at light intensities of 30000 and 8000 lux respectively.

\section{Preparation and analysis of test substrates}

Fish serum was prepared from mixed blood obtained after decapitation of carp (Cyprinus carpio). Separation into molecular size classes was performed by centrifugal filtration with Centricon 
or Centriprep units (Amicon, Beverley, Massachusetts). Polyanionic glycosaminoglycans in serum were precipitated with Alcian blue by modified methods after Whitehead (1978) as described elsewhere (Haas et al. 1990) and then removed by centrifugation. Proteins were removed from serum by treatment with $10 \%$ trichloracetic acid (TCA) solution for $30 \mathrm{~min}$ on ice and centrifugation. TCA was removed from the supernatant with diethylether. Proteins in serum were also hydrolysed with trypsin (Type III, Sigma, St Louis, Missouri; 2 successive treatments with 10 units $/ \mathrm{ml}, \mathrm{pH} 7 \cdot 6$ for $4 \mathrm{~h}$ at $25{ }^{\circ} \mathrm{C}$ ) and then with protease from Streptomyces griseus (pronase E, Sigma; 2 treatments with 2 units $/ \mathrm{ml}$, $\mathrm{pH} 7 \cdot 5$ for $4 \mathrm{~h}$ at $37^{\circ} \mathrm{C}$ ). Hydrolysis was verified with the Bradford protein assay. Different incubating conditions modified the stimulating activity of the substrates. Therefore, 3 control substrates had to be run under identical conditions: modifying reagent (e.g. enzyme) without substrate, substrate without reagent (substrate 'similarly treated', i.e. positive control), and buffer only.

Amino acid analysis was performed by highperformance liquid chromatography (HPLC) on a RP-18 column applying pre-column derivatization with $O$-phthaldialdehyde and fluorescence detection as described elsewhere (Haas et al. 1995). Monosaccharides were detected by gaschromatography on a ZB-5 column (Phenomenex, Aschaffenburg, Germany) after derivatization with Tri-Sil Z (Pierce, Rockford, Illinois) and incubation at $60{ }^{\circ} \mathrm{C}$ for $1 \mathrm{~h}$. Osmolarity of the solutions was controlled using a semi-micro osmometer (Type digital, Knauer, Berlin, Germany).

\section{Statistical methods}

Replicate percentage data were transformed by arcsine-square root transformation to obtain approximately normally distributed data. Means were compared using a multiple $t$-test procedure (TukeyLSD-test) after One-Way Anova and test for homogeneity. Mean values and standard errors (s.E.) were calculated from the transformed data and were retransformed thereafter. For simplification, only the larger of the 2 different s.E. is indicated in the tables. In experiments on orientation of diplostomula within fish fins a $\chi^{2}$-procedure was used to test for statistically significant differences from an equal distribution.

\section{RESULTS}

\section{Orientation in the tail fin of fish}

D. spathaceum cercariae readily penetrated tail fins of guppy. Fin rays restricted their path of migration mainly in an antero-posteriad direction. Most diplostomula burrowed directly towards veins and

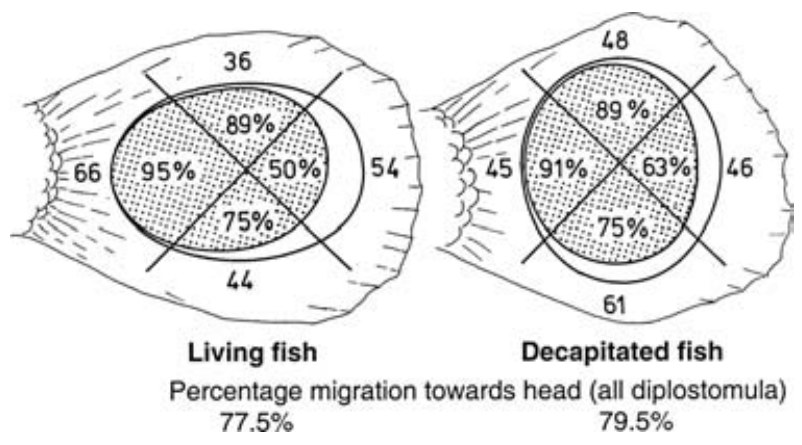

Fig. 1. Choice of cranial direction of Diplostomum spathaceum cercariae after penetration into the tail fin of a live (left) and decapitated guppy (right). The figure shows the orientation of the larvae during penetration (number of cercariae, initial direction) and the percentage of these larvae migrating in cranial direction after $1200 \mu \mathrm{m}$ of burrowing (spotted). The area of the sectors correlates with the number of cercariae observed. After a longer path of migration all parasites observed shifted to a cranial direction. Data from 200 cercariae and 25 living and 28 decapitated fish individuals.

entered them for further migration. Only 1-3\% of the diplostomula entered arteries located within the fin rays. During penetration, the cercariae showed no preference for any particular direction, but folds in the living fin forced the attached organisms preferentially in a antero-posteriad direction (Fig. 1). During their further path of migration the diplostomula shifted towards a cranial direction. This was already significant when they had migrated a distance of $1200 \mu \mathrm{m}$ (approximating 6.5 body lengths) in the fins of living and decapitated fish (Fig. 1). The capability of the parasites to shift to an orientation in a cranial direction was independent from the streaming blood as their orientation was not altered in blocked veins (Table 1A). It was even independent of living cells, as cranial migration occurred also in fins after their treatment with liquid nitrogen (Table 1D). The signalling cues did not originate exclusively from the body of the fish, as the parasites also chose a cranial direction in isolated fins and in pieces of fins, and perhaps even when fin pieces were reversely connected to the fish (Table 1B). The speed of diplostomular migration was below $40 \mu \mathrm{m} / \mathrm{min}$ when they traversed tissues, but in the veins they migrated up to $3-4 \mathrm{~mm} / \mathrm{min}$. The mean speed of migration in fins of living guppies over distances of $1198 \pm 546(357-3071) \mu \mathrm{m}$ was $276 \pm 200 \mu \mathrm{m} / \mathrm{min}$ (38-1250 $\mu \mathrm{m} / \mathrm{min}$ using data from 51 diplostomula). In the decapitated fish, the parasites migrated slower and showed more turns than in the living fish (Table 1C). In the fins of living or decapitated fish, only few diplostomula left the tissue after penetration, and most of these had migrated in a posterior direction (Table 1C). However, a high percentage of migrating diplostomula left the fins with killed cells (Table 1D). 
Table 1. Orientation of diplostomula in the tail fin of guppies

(Data for $1200 \mu \mathrm{m}$ distance of migration after penetration.)

\begin{tabular}{|c|c|c|c|}
\hline & $\begin{array}{l}\text { Percentage } \\
\text { diplostomula } \\
\text { responding }\end{array}$ & $\begin{array}{l}\text { Number of } \\
\text { diplostomula } \\
\text { observed }\end{array}$ & $\begin{array}{l}P \text { vs } 50 \% \\
\text { distribution } \\
\left(\chi^{2} \text {-test }\right)\end{array}$ \\
\hline \multicolumn{4}{|c|}{ (A) Effect of blood flow on migration in cranial direction in veins, living fish } \\
\hline Vein with flowing blood & $80 \cdot 5$ & 123 & $<0 \cdot 001^{\mathrm{a}}$ \\
\hline Vein, blood flow blocked & $74 \cdot 0$ & 73 & $0 \cdot 003^{\mathrm{a}}$ \\
\hline \multicolumn{4}{|c|}{ (B) Orientation in cranial direction in isolated tail fin pieces of decapitated fish ${ }^{b}$} \\
\hline Isolated tail fin pieces & $64 \cdot 0$ & 125 & $0 \cdot 02$ \\
\hline Reversely attached fin pieces & $57 \cdot 1$ & 63 & $0 \cdot 4$ \\
\hline \multicolumn{4}{|l|}{ (C) Migration in living (L) and decapitated (D) fish } \\
\hline No change of direction, $\mathrm{L}$ & $33 \cdot 5$ & 200 & $-^{c}$ \\
\hline No change of direction, $\mathrm{D}$ & $20 \cdot 0$ & 200 & - $^{\mathrm{c}}$ \\
\hline Change of direction $\left(>3\right.$ turns of $\left.90^{\circ}\right) \mathrm{L}$ & $4 \cdot 5$ & 200 & $-\mathrm{d}$ \\
\hline Change of direction $\left(>3\right.$ turns of $\left.90^{\circ}\right) \mathrm{D}$ & $18 \cdot 5$ & 200 & - $^{\mathrm{d}}$ \\
\hline Leaving tissue during migration, $\mathrm{L}$ & $4 \cdot 0$ & 200 & - \\
\hline Percent thereof migrating in posterior direction, $\mathrm{L}$ & $100 \cdot 0$ & 8 & - \\
\hline Leaving tissue during migration, D & $6 \cdot 5$ & 200 & - \\
\hline Percent thereof migrating in posterior direction, D & $76 \cdot 9$ & 13 & - \\
\hline \multicolumn{4}{|c|}{ (D) Orientation in dead fish (after treatment with liquid nitrogen) } \\
\hline Migration in cranial direction & $66 \cdot 6$ & 96 & $0 \cdot 03$ \\
\hline Leaving the fin after penetration & $38 \cdot 1$ & 168 & - \\
\hline
\end{tabular}

a Veins were blocked by rubber bands and by other migrating diplostomula. There was no significant difference between orientation in veins with or without blood flow $\left(P=0 \cdot 3, \chi^{2}\right.$-test $)$.

$\mathrm{b}$ Direction cranial relative to the original position of the fin pieces. Isolated tail fin pieces were sealed at the cuts with Ringer-agar. Tail fin pieces ( $3 \mathrm{~mm}$ wide) were cut at both ends and fixed at the fin in reverse position (relative to the longitudinal axis of the fish) with Ringer-agar.

c,d Orientation within living and decapitated fish differs significantly $\left({ }^{\mathrm{c}} P=0.002 ;{ }^{\mathrm{d}} P<0 \cdot 001 ; \chi^{2}\right.$-test).

\section{Orientation when migrating in agar}

The cercariae penetrated the agar in the Wchambers, and in agar with fish Ringer or other electrolyte solutions, they survived for more than $12 \mathrm{~h}$ and showed significant chemotactic orientation. Fish serum was attractive and the stimulating compounds were contained in a fraction with molecular sizes below $3 \mathrm{kDa}$ (Table 2A). This fraction was attractive independent of its $\mathrm{pH}$ (Table 2B). The stimuli could not be precipitated with Alcian blue like the stimuli for D. spathaceum cercarial penetration behaviour (Haas et al. 2002b) (Table 2C). Also, removal of proteins with TCA had no effect on attractiveness (Table 2D) and protease digestion increased the attraction of serum and also its content of free amino acids (Table 2E, F). However, amino acids were not attractive in concentrations as detected in serum, and arginine, the attractant for S. mansoni and T. ocellata schistosomula (Grabe and Haas, 2004a), had no effect on the orientation of D. spathaceum larvae at a wide range of concentrations (Table 2F). However, arginine integrated in tetrapeptides attracted the D. spathaceum larvae within narrow concentration ranges. A peptide with terminally positioned arginine attracted at lower concentrations than a peptide with subterminally positioned arginine and a peptide without arginine showed no attraction at all (Table 2F; Fig. 2).
Another attractive compound of serum was D-glucose, which stimulated the larvae in a concentration as detected in the serum fraction and in 2 other concentration ranges (Table $2 \mathrm{G}$, Fig. 2). The response to D-glucose was relatively specific, as among other carbohydrates tested, only D-mannose and D-maltotriose were attractive and D-glucosamine had a repellent effect at various concentrations (Table 2G, H).

A concentration gradient of $\mathrm{NaCl}$ attracted the larvae (Table 2I). This was not due to the increasing osmolarity of the $\mathrm{NaCl}$ gradient as a similar increase of osmolarity with mannitol was not attractive (Table 2I). The chemical stimulus in the increasing gradients of electrolyte solutions was the $\mathrm{Cl}$ ion, as a replacement of the $\mathrm{Na}$ ions by $\mathrm{K}$ ions had no effect ( $\mathrm{KCl}$ solutions were as attractive as $\mathrm{NaCl}$ solutions; Table 2J) and as electrolyte solutions were not attractive, when $\mathrm{Cl}$-ions were replaced by $\mathrm{PO}_{4}$-ions (Table $2 \mathrm{~K}$ ). The cercariae avoided substrates without $\mathrm{Cl}$-ions such as water or sodium phosphate (Table 2K).

The compound to which the diplostomula were most sensitive was melatonin. It was attractive at a very low concentration, but only in a narrow concentration range (Table $2 \mathrm{~L}$ ). The concentration of melatonin in fish retina is higher than in the surrounding tissues and this could lead to an accumulation of the parasites in the retina. However, the 
Table 2. Chemo-orientation of diplostomula in agar towards carp serum, its chemical components and pure chemicals

(The larvae migrated in $\mathrm{W}$-choice-chambers and were exposed to chemical concentration gradients, created by application of defined concentrations of the attractants into W-chambers. The agar and test and control substrates contained Ringer solution $^{\mathrm{a}}$ unless otherwise noted $(\mathrm{I}, \mathrm{J}, \mathrm{K})$.)

\begin{tabular}{|c|c|c|c|}
\hline & $\begin{array}{l}\text { Concentration } \\
\text { applied }\end{array}$ & $\begin{array}{l}\text { Orientation } \\
\text { towards } \\
\text { substrate } \% \pm \text { s.E. }\end{array}$ & $\begin{array}{l}\text { Number of } \\
\text { diplostomula } \\
\text { (Number of } \\
\text { replicates) }\end{array}$ \\
\hline \multicolumn{4}{|l|}{ (A) Serum: molecular filtration } \\
\hline Crude serum & $52 \mathrm{mg} / \mathrm{ml}$ & $76 \cdot 2 \pm 3 \cdot 3 *$ & $96(8)$ \\
\hline Serum $>3 \mathrm{kDa}$ & From $52 \mathrm{mg} / \mathrm{ml}$ & $55 \cdot 9 \pm 8 \cdot 0$ & $72(7)$ \\
\hline Serum $<3 \mathrm{kDa}$ & From $52 \mathrm{mg} / \mathrm{ml}$ & $73 \cdot 0 \pm 5 \cdot 9 *$ & $115(8)$ \\
\hline Serum $>3 \mathrm{kDa}+<3 \mathrm{kDa}$ & From $52 \mathrm{mg} / \mathrm{ml}$ & $71 \cdot 4 \pm 3 \cdot 2 *$ & $117(8)$ \\
\hline Control (Ringer solution) & - & $47 \cdot 4 \pm 2 \cdot 5$ & $77(8)$ \\
\hline \multicolumn{4}{|l|}{ (B) Effect of $\mathrm{pH}$ of serum fraction $<3 \mathrm{kDa}$} \\
\hline $\mathrm{pH} 6 \cdot 0$ & From $52 \mathrm{mg} / \mathrm{ml}$ & $79 \cdot 0 \pm 4 \cdot 8^{*}$ & $188(10)$ \\
\hline $\mathrm{pH} 8 \cdot 0$ & From 52 mg/ml & $82 \cdot 3 \pm 3 \cdot 5 *$ & $178(10)$ \\
\hline pH 9.0 & From $52 \mathrm{mg} / \mathrm{ml}$ & $80 \cdot 0 \pm 2 \cdot 5 *$ & $210(10)$ \\
\hline Control (fraction $<3 \mathrm{kDa}, \mathrm{pH} 7 \cdot 0$ ) & From $52 \mathrm{mg} / \mathrm{ml}$ & $79 \cdot 7 \pm 5 \cdot 0 *$ & $225(10)$ \\
\hline Control (Ringer solution) & - & $51 \cdot 9 \pm 8 \cdot 9$ & $134(10)$ \\
\hline \multicolumn{4}{|c|}{ (C) Serum: removal of polyanionic glycosaminoglycans by Alcian-blue treatment } \\
\hline Serum, similarly treated & $52 \mathrm{mg} / \mathrm{ml}$ & $78 \cdot 9 \pm 2 \cdot 2 *$ & $330(5)$ \\
\hline Serum, Alcian-blue treated & From $52 \mathrm{mg} / \mathrm{ml}+0 \cdot 02 \%$ & $77 \cdot 9 \pm 2 \cdot 9 *$ & $486(5)$ \\
\hline Alcian-blue, similarly treated & $0.02 \%$ & $50 \cdot 2 \pm 1 \cdot 9$ & $260(5)$ \\
\hline Control (Ringer solution) & - & $50 \cdot 6 \pm 2 \cdot 3$ & $210(5)$ \\
\hline \multicolumn{4}{|l|}{ (D) Serum: removal of proteins with TCA } \\
\hline Serum, similarly treated & $52 \mathrm{mg} / \mathrm{ml}$ & $67 \cdot 4 \pm 1 \cdot 9 *$ & $219(10)$ \\
\hline Serum, TCA treated & From $52 \mathrm{mg} / \mathrm{ml}$ & $66 \cdot 2 \pm 2 \cdot 4 *$ & $201(10)$ \\
\hline TCA, similarly treated & - & $49 \cdot 7 \pm 1 \cdot 5$ & $132(10)$ \\
\hline Control (Ringer solution) & - & $50 \cdot 3 \pm 1 \cdot 8$ & $125(10)$ \\
\hline \multicolumn{4}{|c|}{ (E) Serum: digestion with trypsin and then with pronase $\mathrm{E}^{\mathrm{c}}$} \\
\hline Serum, similarly treated & $52 \mathrm{mg} / \mathrm{ml}$ & $80 \cdot 5 \pm 1 \cdot 5 *$ & $320(10)$ \\
\hline Serum, digested ${ }^{\mathrm{c}}$ & - & $94 \cdot 5 \pm 1 \cdot 3 * \mathrm{~d}$ & $227(10)$ \\
\hline Serum, digested, diluted $1: 10$ & - & $79 \cdot 9 \pm 1 \cdot 6 *$ & $366(10)$ \\
\hline Serum, digested, diluted $1: 100$ & - & $61 \cdot 6 \pm 3 \cdot 7 *$ & $179(10)$ \\
\hline Enzymes, similarly treated & - & $49 \cdot 2 \pm 1 \cdot 1$ & $211(10)$ \\
\hline Control (Ringer solution) & - & $50 \cdot 3 \pm 1 \cdot 2$ & $160(10)$ \\
\hline \multicolumn{4}{|c|}{ (F) Amino acids and tetrapeptides (pure chemicals) } \\
\hline $\begin{array}{l}\text { Amino acids, concentrations as } \\
\text { detected in serum }<3 \mathrm{kDa}\end{array}$ & e & $58 \cdot 1 \pm 5 \cdot 4$ & $60(10)$ \\
\hline \multirow[t]{2}{*}{ Arginine } & $100 \mu \mathrm{M}^{\mathrm{f}}$ & $49 \cdot 3 \pm 6 \cdot 2$ & $140(14)$ \\
\hline & $1000 \mu \mathrm{M}^{\mathrm{f}}$ & $54 \cdot 3 \pm 6 \cdot 2$ & $141(14)$ \\
\hline Peptide arg-glu-asp-ser & $2 \cdot 5 \mu \mathrm{M}$ & $67 \cdot 1 \pm 2 \cdot 2 *$ & $153(8)$ \\
\hline Peptide gly-arg-gly-asp & $25 \mu \mathrm{M}$ & $72 \cdot 2 \pm 2 \cdot 1 *$ & $170(8)$ \\
\hline Peptide val-gly-ser-glu & $25 \mu \mathrm{M}$ & $50 \cdot 3 \pm 1 \cdot 2$ & $123(8)$ \\
\hline $\begin{array}{l}\text { Control (serum fraction }<3 \mathrm{kDa} \\
\text { in Ringer solution) }\end{array}$ & From $52 \mathrm{mg} / \mathrm{ml}$ & $70 \cdot 8 \pm 4 \cdot 1 *$ & $121(11)$ \\
\hline Control (Ringer solution) & - & $50 \cdot 0 \pm 2 \cdot 2$ & $89(13)$ \\
\hline \multicolumn{4}{|c|}{ (G) Carbohydrates: $\mathrm{C}_{6}$-monohydrates and derivates (pure chemicals) } \\
\hline $\begin{array}{l}\text { D-Glucose, concentration as } \\
\text { detected in serum }<3 \mathrm{kDa}\end{array}$ & $1 \cdot 1 \mathrm{~mm}$ & $60 \cdot 9 \pm 3 \cdot 4 *$ & $120(10)$ \\
\hline D-Glucose & $5 \cdot 0 \mathrm{mM}$ & $64 \cdot 5 \pm 3 \cdot 4 *$ & $134(10)$ \\
\hline Sorbitol & $5 \cdot 0 \mathrm{mM}$ & $53 \cdot 4 \pm 7 \cdot 6$ & $99(10)$ \\
\hline D-Mannose & $5 \cdot 0 \mathrm{mM}$ & $63 \cdot 6 \pm 5 \cdot 2 *$ & $114(15)$ \\
\hline Mannitol & $5 \cdot 0 \mathrm{mM}$ & $51 \cdot 4 \pm 5 \cdot 1$ & $80(14)$ \\
\hline \multirow[t]{2}{*}{ D-Glucosamine } & $5 \cdot 0 \mathrm{~mm}^{\mathrm{g}}$ & $36 \cdot 2 \pm 2 \cdot 0 *$ & $127(10)$ \\
\hline & $1 \cdot 0 \mathrm{nM}^{\mathrm{g}}$ & $43 \cdot 3 \pm 2 \cdot 2 *$ & $85(8)$ \\
\hline D-Rhamnose & $5 \cdot 0 \mathrm{mM}$ & $51 \cdot 3 \pm 3 \cdot 8$ & $133(10)$ \\
\hline D-Galactose & $5 \cdot 0 \mathrm{mM}$ & $51 \cdot 3 \pm 6 \cdot 1$ & $140(13)$ \\
\hline Control (Serum $<3 \mathrm{kDa}$ in Ringer solution) & From $52 \mathrm{mg} / \mathrm{ml}$ & $71 \cdot 2 \pm 1 \cdot 8^{*}$ & $145(12)$ \\
\hline Control (Ringer solution) & - & $51 \cdot 5 \pm 6 \cdot 4$ & $54(12)$ \\
\hline \multicolumn{4}{|c|}{ (H) Carbohydrates: $\mathrm{C}_{5}$-monohydrates and an oligosaccharide (pure chemicals) } \\
\hline D-Arabinose & $5 \cdot 0 \mathrm{mM}$ & $49 \cdot 7 \pm 3 \cdot 9$ & $104(10)$ \\
\hline D-Ribose & $5 \cdot 0 \mathrm{mM}$ & $58 \cdot 6 \pm 6 \cdot 4$ & $91(10)$ \\
\hline
\end{tabular}




\begin{tabular}{|c|c|c|c|}
\hline & $\begin{array}{l}\text { Concentration } \\
\text { applied }\end{array}$ & $\begin{array}{l}\text { Orientation } \\
\text { towards } \\
\text { substrate } \% \pm \text { s.E. }\end{array}$ & $\begin{array}{l}\text { Number of } \\
\text { diplostomula } \\
\text { (Number of }_{\text {replicates) }} \text { b }\end{array}$ \\
\hline D-Xylose & $5 \cdot 0 \mathrm{mM}$ & $56 \cdot 8 \pm 5 \cdot 3$ & $145(15)$ \\
\hline D-Maltotriose & $5 \cdot 0 \mathrm{mM}$ & $61 \cdot 9 \pm 2 \cdot 8^{*}$ & $144(10)$ \\
\hline Control (Serum $<3 \mathrm{kDa}$ in Ringer solution) & From $52 \mathrm{mg} / \mathrm{ml}$ & $71 \cdot 4 \pm 2 \cdot 1 *$ & $108(10)$ \\
\hline Control (Ringer solution) & - & $50 \cdot 0 \pm 1 \cdot 9$ & $104(10)$ \\
\hline \multicolumn{4}{|c|}{ (I) Altering osmolarity with mannitol (agar and control substrates $300 \mathrm{mOsm} \mathrm{NaCl}$ ) } \\
\hline $\mathrm{NaCl}, 450 \mathrm{mOsm}$ & $450 \mathrm{mOsm}$ & $64 \cdot 9 \pm 9 \cdot 4 *$ & $57(7)$ \\
\hline $\mathrm{NaCl}, 150 \mathrm{mOsm}+$ mannitol, $150 \mathrm{mOsm}$ & $150+150 \mathrm{mOsm}$ & $37 \cdot 5 \pm 7 \cdot 9 *$ & $96(8)$ \\
\hline $\mathrm{NaCl}, 300 \mathrm{mOsm}+$ mannitol, $150 \mathrm{mOsm}$ & $300+150 \mathrm{mOsm}$ & $49 \cdot 8 \pm 4 \cdot 9$ & $107(8)$ \\
\hline Control (Serum $<3 \mathrm{kDa}$ in $\mathrm{NaCl}, 300 \mathrm{mOsm}$ ) & From $52 \mathrm{mg} / \mathrm{ml}$ & $79 \cdot 2 \pm 3 \cdot 6^{*}$ & $173(8)$ \\
\hline Control ( $\mathrm{NaCl} 300 \mathrm{mOsm})$ & - & $52 \cdot 4 \pm 5 \cdot 9$ & $84(8)$ \\
\hline \multicolumn{4}{|c|}{ (J) Sodium, potassium and chloride ions (agar and control substrates $300 \mathrm{mOsm} \mathrm{NaCl}$ ) } \\
\hline $\mathrm{NaCl}, 450 \mathrm{mOsm}$ & $450 \mathrm{mOsm}$ & $64 \cdot 5 \pm 8 \cdot 6^{*}$ & $62(10)$ \\
\hline $\mathrm{NaCl}, 300 \mathrm{mOsm}+\mathrm{KCl}, 150 \mathrm{mOsm}$ & $300+150 \mathrm{mOsm}$ & $66 \cdot 7 \pm 10 \cdot 4 *$ & $69(10)$ \\
\hline $\mathrm{KCl}, 450 \mathrm{mOsm}$ & $450 \mathrm{mOsm}$ & $61 \cdot 9 \pm 14 \cdot 0 *$ & $42(10)$ \\
\hline $\mathrm{KCl}, 300 \mathrm{mOsm}$ & $300 \mathrm{mOsm}$ & $45 \cdot 5 \pm 6 \cdot 8$ & $66(10)$ \\
\hline Control (Serum $<3 \mathrm{kDa}$ in $\mathrm{NaCl}, 300 \mathrm{mOsm}$ ) & From $52 \mathrm{mg} / \mathrm{ml}$ & $80 \cdot 5 \pm 5 \cdot 7 *$ & $128(10)$ \\
\hline Control ( $\mathrm{NaCl}, 300 \mathrm{mOsm})$ & $300 \mathrm{mOsm}$ & $44 \cdot 0 \pm 7 \cdot 6$ & $100(10)$ \\
\hline \multicolumn{4}{|c|}{ (K) Replacement of chloride ions by phosphate ions ${ }^{\mathrm{h}}$ (agar and control substrates $150 \mathrm{~mm} \mathrm{NaCl}$ ) } \\
\hline $\mathrm{NaCl}, 225 \mathrm{mM}$ & $225 \mathrm{mM}$ & $63 \cdot 0 \pm 4 \cdot 0 *$ & $138(8)$ \\
\hline $\mathrm{Na}[\mathrm{P}]^{\mathrm{h}}, 225 \mathrm{mM}$ & $225 \mathrm{~mm}$ & $38 \cdot 5 \pm 6 \cdot 4 *$ & $86(8)$ \\
\hline $\mathrm{Na}[\mathrm{P}]^{\mathrm{h}}, 150 \mathrm{mM}$ & $150 \mathrm{mM}$ & $39 \cdot 5 \pm 5 \cdot 5 *$ & $85(8)$ \\
\hline $\mathrm{H}_{2} \mathrm{O}$ & - & $38 \cdot 3 \pm 3 \cdot 0 *$ & $130(8)$ \\
\hline $\mathrm{NaCl}, 150 \mathrm{~mm}+\mathrm{Na}[\mathrm{P}], 75 \mathrm{~mm}$ & $150+75 \mathrm{~mm}$ & $43 \cdot 7 \pm 4 \cdot 6$ & $134(6)$ \\
\hline Control (Serum $<3 \mathrm{kDa}$ in $\mathrm{NaCl}, 150 \mathrm{~mm}$ ) & From $52 \mathrm{mg} / \mathrm{ml}$ & $78 \cdot 3 \pm 3 \cdot 9 *$ & $220(8)$ \\
\hline Control (NaCl, $150 \mathrm{~mm})$ & $150 \mathrm{~mm}$ & $46 \cdot 9 \pm 4 \cdot 8$ & $147(6)$ \\
\hline \multicolumn{4}{|l|}{ (L) Melatonin (pure chemical) } \\
\hline \multirow[t]{2}{*}{ Melatonin } & $1 \mathrm{ng} / \mathrm{ml}(4 \cdot 3 \mathrm{pM})^{\mathrm{i}}$ & $70 \cdot 9 \pm 4 \cdot 9 *$ & $96(10)$ \\
\hline & $0 \cdot 1 \mathrm{ng} / \mathrm{ml}(0 \cdot 4 \mathrm{pM})^{\mathrm{i}}$ & $66 \cdot 4 \pm 4 \cdot 1 *$ & $98(9)$ \\
\hline Control (Serum $<3 \mathrm{kDa}$ in Ringer solution) & From $52 \mathrm{mg} / \mathrm{ml}$ & $72 \cdot 5 \pm 5 \cdot 3 *$ & $116(10)$ \\
\hline Control (Ringer solution) & - & $50 \cdot 7 \pm 2 \cdot 6$ & $96(12)$ \\
\hline
\end{tabular}

* $P<0 \cdot 01$ vs control (Tukey multiple $t$-test).

${ }^{a}$ Fish Ringer according to Haas $(1974 b), \mathrm{mEq} / \mathrm{l}: \mathrm{Na}^{+}$120, $\mathrm{K}^{+} 4, \mathrm{Ca}^{2+}$ 5, $\mathrm{Mg}^{2+} 4, \mathrm{Cl}^{-}$118, $\mathrm{SO}_{4}^{2-}$ 5, $\mathrm{HCO}_{3}^{-} 10$.

b Total number of diplostomula leaving the central arm of the $\mathrm{W}$-chamber (and number of replicates) per tested substrate.

c The content of amino acids in serum increased after digestion from 11.9 to $92.7 \mathrm{~mm}$ and the osmolarity from 269 to $291 \mathrm{mOsm} / 1$.

d Attraction significantly different from that of serum similarly treated, $P<0 \cdot 001$ (Tukey multiple $t$-test).

e Concentration of amino acids, as detected in serum fraction $<3 \mathrm{kDa}(\mu \mathrm{M})$ : asp 136 , glu 151 , asn 128 , ser 811 , his 412 , gly 840, thr 325, arg 127, ala 610, tau 405, tyr 176, val 254, met 62, ile 196, phe 206, leu 203, orn 62, lys 275.

${ }_{\mathrm{f}}$ No significant attraction at other concentrations as well $(0 \cdot 1,0 \cdot 25,0 \cdot 5,1 \cdot 0,2 \cdot 0,10,25,50,500,5000,10000 \mu \mathrm{M})$.

g Similar repellent effect at other concentrations $(0 \cdot 01,0 \cdot 1,1 \cdot 0,10,50,75,100 \mu \mathrm{M})$.

h $\mathrm{Na}_{2} \mathrm{HPO}_{4}$ and $\mathrm{NaH}_{2} \mathrm{PO}_{4}$, adjusted to the desired $\mathrm{Na}^{+}$-concentration and $\mathrm{pH} 7 \cdot 0$.

${ }^{i}$ Weak (not statistically significant) effect at concentrations of 10 and $0.01 \mathrm{ng} / \mathrm{ml}$, no effect at higher concentrations (100, $500,1000 \mathrm{ng} / \mathrm{ml})$.

parasites leave the retina and migrate towards the eye lens, although they are strongly attracted by melatonin. A cue for their orientation towards the lens could be the direction of light radiation within the eyes. Therefore, we investigated whether the migrating diplostomula shifted to a positive photoorientation when stimulated with melatonin. However, melatonin failed to stimulate orientation towards light at concentrations of 1 and $100 \mathrm{ng} / \mathrm{ml}$ and light intensities of 30000 and 8000 lux $(P$ vs control $0 \cdot 7-1 \cdot 0 ; 343-706$ responding diplostomula; 13-16 replicates).

\section{DISCUSSION}

The navigation of D. spathaceum diplostomula along blood vessels and through tissues towards the eye and then to the lens is very complex and our in vivo studies focus only on orientation within the tail fin towards veins and in an anterior direction. Our in vitro experiments revealed information on the chemo- and photo-orientation of the diplostomula, but we can only speculate on the role of these responses during the navigation process. We suggest that the behaviour of migrating diplostomula 


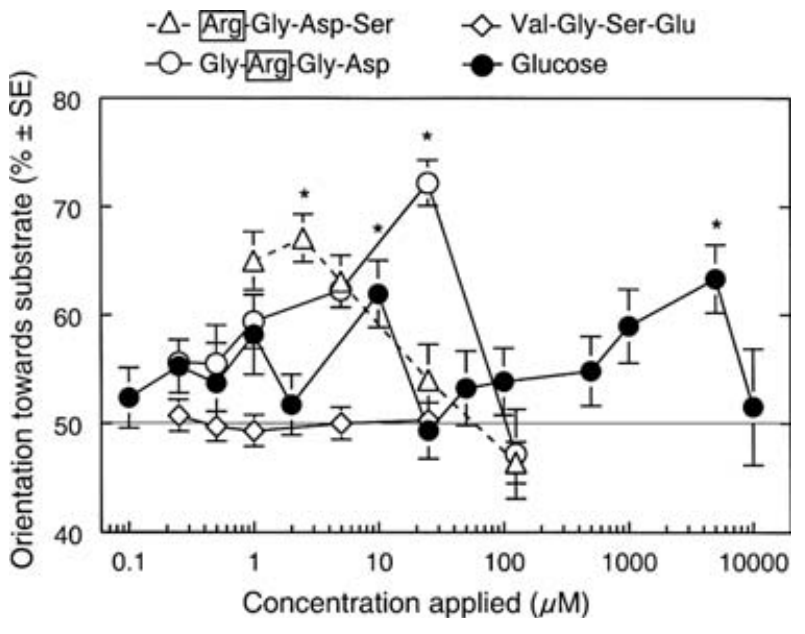

Fig. 2. Chemo-orientation of Diplostomum spathaceum diplostomula in the $\mathrm{W}$-chamber. Effect of varying concentration gradients of tetrapeptides and glucose, created by application of different concentrations of the compounds into W-chambers; * significant $v s$ buffered Ringer as control $(P<0 \cdot 001$, Tukey multiple $t$-test $)$; data from 62-295 diplostomula showing chemo-orientation per concentration, $6-10$ replicates.

consists of discrete units, and that they, as in their host-finding behaviour, respond to different host cues in each of these units. The observed responses may have functions in 4 behavioural phases during migration within the fish host, as summarized in Fig. 3 and as presented below.

(1) Migration towards deeper skin layers and avoidance of perforation of the covering skin surface layers. To avoid accidental perforation of the skin surface layers is important for the survival of the migrating diplostomula as discussed also for schistosomula of S. mansoni and T. ocellata (Grabe and Haas, 2004a). In fact, the diplostomula successfully avoided orientation back to the skin surface when the fin tissues were still living (living and decapitated fish). However, when the cells of the fins were killed, many diplostomula left the tissues. So, the cues used to detect the direction towards skin surface or deeper skin layers appear weakened in dead tissue but they still exist. As the diplostomula in vitro migrate along increasing concentration gradients of $\mathrm{Cl}^{-}$and avoid decreasing gradients, $\mathrm{Cl}^{-}$gradients could be the landmark that enables their remaining in the skin. However, little is known about the osmotic conditions and the distribution of electrolytes within fin tissues. In freshwater fish, $\mathrm{NaCl}$ uptake seems to be achieved by $\mathrm{Na}^{+} / \mathrm{H}^{+}$and $\mathrm{Cl}^{-} / \mathrm{HCO}_{3}$ exchangers, mainly in cells of gills, but the further transport of $\mathrm{Na}^{+}$and $\mathrm{Cl}^{-}$in the skin tissues is not understood and the published data on concentrations of these ions in fish tissues are controversial, even in studies of gill tissues (reviewed by Marshall, 2002; Perry et al. 2003; Kirschner, 2004; Evans et al. 2005).
There is also a high influx of water (50\% of the body water per $\mathrm{h}$ ), which is compensated by excretion of dilute urine. The water influx occurs presumably mainly across the gills, but it could also occur in the skin. So, there might be concentration gradients of $\mathrm{Cl}^{-}$from the body surface towards deeper tissues, which could be used by the diplostomula as directing cues.

Another strategy of the migrating diplostomula could be to follow an increasing concentration gradient of glucose from the skin surface to deeper tissues. Such a concentration gradient exists in mammals and seems to be used by migrating schistosomula of S. mansoni and T. ocellata (Grabe and Haas, 2004a). As fish show a persistent hyperglycaemia (Moon, 2001; Hemre et al. 2002), similar conditions can also be expected in fish skin.

An orientation back to the skin surface might also be prevented by the repellent effect of glucosamine on migrating diplostomula. This avoidance behaviour seems to be important for the parasites, as they respond very sensitively to gradients that establish at concentrations as low as $1 \mathrm{nM}$. It might reflect an adaptation to migration in a fish host, as the schistosomula of $S$. mansoni and $T$. ocellata are not repelled by glucosamine (Grabe and Haas, 2004a). Fish skin contains glycosaminoglycans (GAGs) in surface mucus and epidermal mucus-secreting cells. Degradation products of GAGs from fish skin surface mucus seem to serve as very effective kairomones for shrimps, crabs, and snails (Forward and Rittschof, 1999, 2000; Rahman et al. 2000). Disaccharides containing sulfated and acetylated amines were very effective signals among the fish mucus degradation products, but glucosamine was also recognized, at least by nauplius larvae of the brine shrimp (Artemia franciscana) (Forward and Rittschof, 1999). Such amino sugars may occur as degradation products of mucus and during synthesis of the polysaccharides in epidermal mucus secreting cells (Lumsden and Ferguson, 1994); they may then exert their repellent effect on diplostomula. The hypothesis that amino sugars in skin epithelial cells guide diplostomula back to deeper layers requires further study, in particular on the effect of the more abundant galactosamine (Nakagawa et al. 1988), as well as sulfated and acetylated amino sugars.

Glucosamine and other amino sugars are major compounds of extracellular matrix. So, the sensitive turning away from these sugars could enable the diplostomula to avoid ineffective migration attempts across extracellular matrix, such as cartilage and basal laminas of epithelial layers. Data on the repellent effect of other amino sugars specific for certain tissues could show which tissue types are avoided during the migration. The D. spathaceum diplostomula are (in contrast to schistosomes) also attracted by carbohydrates other than glucose; they 


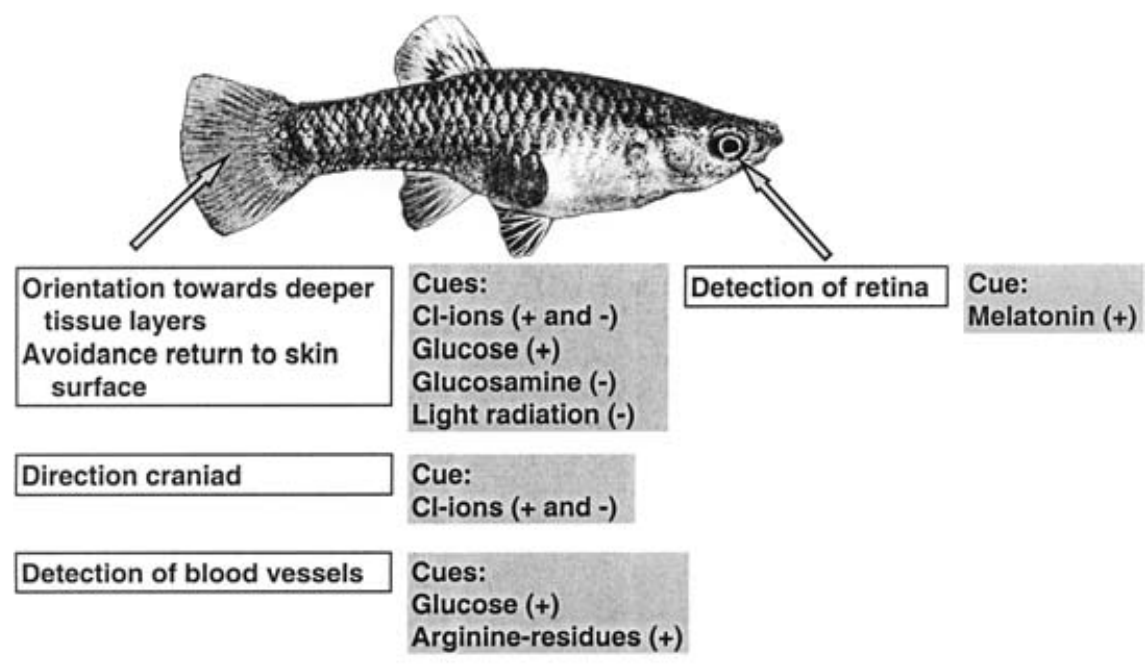

Fig. 3. Hypothetical model of some of the behavioural phases of Diplostomum spathaceum diplostomula when migrating in the fish host (boxes) and supposed cues used for navigation. Diplostomula show chemo-orientation in concentration gradients of glucose and other carbohydrates, peptides with arginine residues, Cl-ions, and melatonin, as well as negative photo-orientation; + , positive, - , negative orientation along increasing concentration gradients or direction of light radiation.

respond to D-mannose and to the trisaccharide maltotriose (and D-glucosamine has a repellent effect). Thus, this fish parasite uses more carbohydrate signals during migration than the parasites of terrestrial vertebrates. The orientation of the diplostomula towards deeper tissue layers could also be enhanced by their negative photo-orientation (Grabe and Haas, 2004b).

(2) Orientation in direction towards the head of the fish. In the tail fin of fish, the diplostomula navigate precisely in the cranial direction. As they enter veins and use them for further migration in the fin, they could use the direction of the blood flow for navigation. However, their orientation is undisturbed when there is no blood flow, and they migrate in a cranial direction in isolated pieces of the fin, even when the cells in the tissues are dead. The parasites seem to follow a local chemical or electrical gradient the nature of which remains to be explained. It is hypothesized that orientation along increasing concentration gradients of $\mathrm{Cl}^{-}$could be involved in this step of site-finding as well. This assumes that osmolarity (which is mainly determined by $\mathrm{NaCl}$ concentration) decreases in a distal direction. However, there seems to be no information on the detailed osmotic conditions in fins, although many studies have dealt with osmoregulation of freshwater fish (reviewed by Karnaky, 1998).

(3) Localization of blood vessels. The diplostomula of D. spathaceum enter veins during their further migration. Schistosomula of S. mansoni and T. ocellata also enter veins of their hosts, and have been hypothesized to locate the vessels by following increasing concentration gradients of glucose and arginine (Haas et al. 2002a; Grabe and Haas, $2004 a)$; D. spathaceum diplostomula may use a similar strategy. They are attracted by glucose (Fig. 2) in gradients that establish at concentrations similar to those in fish plasma, i.e., 2-10 mm (Groff and Zinkl, 1999; Blasco et al. 2001; Hemre et al. 2002). This response may guide them to the blood vessels of fish, which are generally hyperglycaemic (Moon, 2001). Moreover, the parasites respond to a very flat concentration gradient, which establishes at approximately $10 \mu \mathrm{M}$. In addition, schistosomula of $S$. mansoni respond with a second peak of sensitivity to gradients that establish at $10 \mu \mathrm{M}$ glucose, suggesting different biological functions of these 2 peaks of sensitivity to glucose gradients. However, as discussed for $S$. mansoni schistosomula (Grabe and Haas, 2004a), hypotheses on the adaptive benefits of the responses remain unresolved, as we have no exact information on the nature of glucose concentration gradients the parasites encounter in the host tissues or in our $\mathrm{W}$-chambers. There may be gradients that are useful for navigation and others that should be avoided. For example, the parasites enter mainly veins, which have a lower glucose content than arteries, but probably higher concentrations than the tissues the parasites encounter during migration. However, the responses might also just result from the activity of 2 different glucose receptors. The response to 2 or 3 different concentration gradients is not a general characteristic of blood-vessel invading digeneans, as the schistosomula of $T$. ocellata respond only to concentration gradients that establish at approximately $1 \mu \mathrm{M}$ glucose (Grabe and Haas, $2004 a)$. 
In contrast to the schistosomula of $S$. mansoni and $T$. ocellata whose response to arginine may enable them to find venules (Grabe and Haas, 2004a) the diplostomula of $D$. spathaceum do not respond to arginine. However, like schistosomula, they are attracted by tetrapeptides containing arginine. Further work should demonstrate whether the diplostomula respond similarly as $S$. mansoni schistosomula to arginine-containing peptides, which occur in endothelial cells, i.e. bradykinin and its fragments, as well as fibronectin. The responses of digenean larvae to peptides with terminal arginine residues is consistent with a variety of other invertebrates that use such molecules as pheromones and kairomones and supports the suggestion that such peptides generally might serve as information molecules in various organisms (Rittschof, 1993; Rittschof and Cohen, 2004). However, not all bloodvessel invading helminths respond to the same cues. Human hookworms responded differently in our W-chamber bioassay. Ancylostoma duodenale was attracted by human serum, but neither glucose nor arginine were the attractants and Necator americanus showed no chemo-orientation at all (Haas et al. 2005).

(4) Recognition of the eye. Ferguson (1943) concluded from an elaborate series of surgical experiments that the eye tissues, even without a lens, provide a stimulus that attracts the diplostomula. Since fish synthesize melatonin in the retina (Tan et al. 2003; Falcon et al. 2003), we examined the effect of melatonin on migrating diplostomula. The parasites were attracted by melatonin at gradients, which established at concentrations of $0 \cdot 1-1 \cdot 0 \mathrm{ng} / \mathrm{ml}$ $(0 \cdot 4-4 \cdot 3 \mathrm{pm})$ melatonin. This concentration range occurs also in fish retina, i.e., in Carassius auratus it ranged from $0 \cdot 5$ to $2 \cdot 5 \mathrm{ng}$ per eye (Iigo et al. 1997) and in Oncorhynchus mykiss from $0 \cdot 8$ to $3 \cdot 4 \mathrm{ng}$ per eye (Zaunreiter et al. 1998). As the melatonin concentration in the fish retina is higher than in plasma, e.g. 9-100 times higher in C. auratus (Iigo et al. 1997), it may be a signal that dipostomula respond to upon contact with the retina. Whether they can also localize the retina following a concentration gradient of melatonin is difficult to evaluate, as ocular melatonin acts in an autocrine or paracrine manner and seems to accumulate in the eye. However, if melatonin reaches the bloodstream (Tan et al. 2003), diplostomula could potentially follow the melatonin signal to locate the retina.

Eventually, diplostomula leave the retina and enter the lens. Then, the response to melatonin must be negated by reactions to other cues. We suggested that a shift to positive photo-orientation could guide the parasites towards the lens, but the diplostomula did not migrate towards light after contact with melatonin in physiological concentrations. Future experiments will hopefully indicate whether the diplostomula follow only increasing concentration gradients of melatonin and do not return in decreasing gradients.

Our findings are only a first step in understanding how diplostomula find their way within the fish host. We still have no information on the behaviour patterns of the parasites in the fish body and in the gills, the main penetration sites of the cercariae. Much experimental work must be performed before we are able to understand the navigation of the diplostomula (and parasites in general) over longer distances. The migration of diplostomula in their fish hosts is a suitable model for such studies, as in vitro experiments and manipulations of the host and its organs can easily be performed.

When we consider the orientation behaviour of the migrating larvae of D. spathaceum, S. mansoni, $T$. ocellata and the human hookworms (Grabe and Haas, 2004a; Haas et al. 2005), it is obvious that each of the species has its unique strategy. The species respond to different types of host signals, and when they use similar signal molecules they react to very different concentration gradients, position of arginine in peptides, etc. This diversity of behaviour also occurs when the larvae follow similar routes, for example when entering blood vessels. It seems that the navigation of parasitic worms within hosts is characterized by a similar high diversity of strategies, as seen in their host-finding behaviour (Haas, 1994, 2003; Haas and Haberl, 1997; Sukhdeo and Sukhdeo, 2004), and much information will be necessary to understand the adaptive benefits of the individual behavioural responses.

This work was supported by the Deutsche Forschungsgemeinschaft. We thank Renate Landgraf and Christina Loy for their expert technical work and the parasitology group of the University of ErlangenNürnberg for snail-collection.

\section{REFERENCES}

Betterton, C. (1974). Studies on the host specificity of the eyefluke, Diplostomum spathaceum, in brown and rainbow trout. Parasitology 69, 11-29.

Blasco, J., Marimon, I., Viaplana, I. and FernandezBorras, J. (2001). Fate of plasma glucose in tissues of brown trout in vivo: effects of fasting and glucose loading. Fish Physiology and Biochemistry 24, 247-258.

Davis, D. J. (1936). Pathological studies on the penetration of the cercariae of the strigeid trematode, Diplostomum flexicaudum. Fournal of Parasitology 22, 329-337.

Erasmus, D. A. (1959). Studies on the morphology, biology and development of a strigeid cercaria (Cercaria $X$ Baylis 1930). Parasitology 48, 312-335.

Evans, D. H., Piermarini, P. M. and Choe, K. P. (2005). The multifunctional fish gill: site of gas exchange, osmoregulation, acid-base regulation, and excretion of nitrogenous waste. Physiological Reviews 85, 97-177.

Falcon, J., Gothilf, Y., Coon, S. L., Boeuf, G. and Klein, D. C. (2003). Genetic, temporal and developmental 
differences between melatonin rhythm generating systems in the teleost fish pineal organ and retina. Fournal of Neuroendocrinology 15, 378-382.

Ferguson, M. S. (1943). Migration and localization of an animal parasite within the host. Fournal of Experimental Zoology 93, 375-401.

Forward, R. B. and Rittschof, D. (1999). Brine shrimp larval photoresponses involved in diel vertical migration: activation by fish mucus and modified amino sugars. Limnology and Oceanography 44, 1904-1916.

Forward, R. B. and Rittschof, D. (2000). Alteration of photoresponses involved in diel vertical migration of a crab larva by fish mucus and degradation products of mucopolysaccharides. Fournal of Experimental Marine Biology and Ecology 254, 277-292.

Grabe, K. and Haas, W. (2004a). Navigation within host tissues: Schistosoma mansoni and Trichobilharzia ocellata schistosomula respond to chemical gradients. International Fournal for Parasitology 34, 927-934.

Grabe, K. and Haas, W. (2004b). Navigation within host tissues: cercariae orientate towards dark after penetration. Parasitology Research 93, 111-113.

Groff, J. M. and Zink1, J. G. (1999). Haematology and clinical chemistry of cyprinid fish. Common carp and goldfish. Veterinary Clinics of North America : Exotic Animal Practice 2, 741-776.

Haas, W. (1974a). Analyse der Invasionsmechanismen der Cercarie von Diplostomum spathaceum. I. Fixation und Penetration. International Fournal for Parasitology 4, 311-319.

Haas, W. (1974b). Analyse der Invasionsmechanismen der Cercarie von Diplostomum spathaceum. II. Chemische Invasionsstimuli. International Fournal for Parasitology 4, 321-330.

Haas, W. (1975). Einfluss von $\mathrm{CO}_{2}$ und pH auf das Fixationsverhalten der Cercarie von Diplostomum spathaceum ('Trematoda). Zeitschrift für Parasitenkunde 46, 53-60.

Haas, W. (1994). Physiological analyses of host-finding behaviour in trematode cercariae: adaptations for transmission success. Parasitology 109 (Suppl.), S15-S29.

Haas, W. (2003). Parasitic worms : strategies of host finding, recognition and invasion. Zoology 106, 349-364.

Haas, W. and Haber1, B. (1997). Host recognition by trematode miracidia and cercariae. In Advances in Trematode Biology (ed. Fried, B. and Graczyk, T. K.), pp. 197-227. CRC Press, Boca Raton, Florida, USA.

Haas, W., Granzer, M. and Brockelman, C. (1990). Opisthorchis viverrini: Finding and recognition of the fish host by the cercariae. Experimental Parasitology 71, 422-431.

Haas, W., Körner, M., Hutterer, E., Wegner, M. and Haberl, B. (1995). Finding and recognition of the snail intermediate host by 3 species of echinostome cercariae. Parasitology 110, 133-142.

Haas, W., Grabe, K., Geis, C., Päch, T., Stoll, K., Fuchs, M., Haber1, B. and Loy, C. (2002a).

Recognition and invasion of human skin by Schistosoma mansoni cercariae: the key-role of L-arginine.

Parasitology 124, 153-167.

Haas, W., Stiegeler, P., Keating, A., Kullmann, B., Rabenau, H., Schönamsgruber, E. and Haberl, $B$. (2002b). Diplostomum spathaceum cercariae respond to a unique profile of cues during recognition of their fish host. International Fournal for Parasitology 32, 1145-1154.

Haas, W., Haberl, B., Syafruddin Idris, I., Kallert, D., Kersten, S. and Stiegeler, P. (2005). Behavioural strategies used by the hookworms Necator americanus and Ancylostoma duodenale to find, recognize and invade the human host. Parasitology Research 95, 30-39.

Hemre, G.-I., Mommsen, T. P. and Krogdahl, A. (2002). Carbohydrates in fish nutrition: effects on growth, glucose metabolism and hepatic enzymes. Aquaculture Nutrition 8, 175-194.

Iigo, M., Furukawa, K., Hattori, A., Ohtani-Kaneko, R., Hara, M., Suzuki, T., Tabata, M. and Aida, K. (1997). Ocular melatonin rhythms in the goldfish, Carassius auratus. Fournal of Biological Rhythms 12, 182-192.

Karnaky, K. J. (1998). Osmotic and ionic regulation. In The Physiology of Fishes (ed. Evans, D. H.), pp. 157-176. CRC Press, Boca Raton, Florida, USA.

Kirschner, L. B. (2004). The mechanism of sodium chloride uptake in hyperregulating aquatic animals. Fournal of Experimental Biology 207, 1439-1452.

Lumsden, J. S. and Ferguson, H. W. (1994). Isolation and partial characterization of rainbow trout (Oncorhynchus mykiss) gill mucin. Fish Physiology and Biochemistry 12, 387-398.

Marshall, W. S. (2002). $\mathrm{Na}^{+}, \mathrm{Cl}^{-}, \mathrm{Ca}^{2+}$ and $\mathrm{Zn}^{2+}$ transport by fish gills: retrospective review and prospective synthesis. Fournal of Experimental Zoology 293, 264-283.

Moon, T. W. (2001). Glucose intolerance in teleost fish: fact or fiction? Comparative Biochemistry and Physiology 129B, 143-249.

Nakagawa, H., Asakawa, M. and Enomoto, N. (1988). Diversity in the carbohydrate moieties of mucus glycoproteins of various fishes. Nippon Suisan Gakkaisi 54, 1653-1658.

Niewiadomska, K. (1984). Present status of Diplostomum spathaceum (Rudolphi, 1819) and differentiation of Diplostomum pseudospathaceum nom. nov. (Trematoda: Diplostomatidae). Systematic Parasitology 6, 81-86.

Niewiadomska, K. and Kiseliene, V. (1994). Diplostomum cercariae (Digenea) in snails from Lithuania. II. Survey of species. Acta Parasitologica 39, 179-186.

Perry, S. F., Shahsavarani, A., Georgalis, T., Bayaa, M., Furimsky, M. and Thomas, S. L. Y. (2003). Channels, pumps, and exchangers in the gill and kidney of freshwater fishes: their role in ionic and acid-base regulation. Fournal of Experimental Zoology 300A, 53-62.

Rahman, Y. J., Forward, R. B. and Rittschof, D. (2000). Responses of mud snails and periwinkles to environmental odors and disaccharide mimics of fish odor. Fournal of Chemical Ecology 26, 679-696.

Ratanarat-Brockelman, C. (1974). Migration of Diplostomum spathaceum (Trematoda) in the fish intermediate host. Zeitschrift für Parasitenkunde 43, 123-134.

Rittschof, D. (1993). Body odors and neutral-basic peptide mimics: a review of responses by marine organisms. American Zoologist 33, 487-493. 
Rittschof, D. and Cohen, J. H. (2004). Crustacean peptide and peptide-like pheromones and kairomones. Peptides 25, 1503-1516.

Sukhdeo, M. V. K. and Sukhdeo, S. C. (1994). Optimal habitat selection by helminths within the host environment. Parasitology 109 (Suppl.) S41-S55.

Sukhdeo, M. V. K. and Sukhdeo, S. C. (2002). Fixed behaviours and migration in parasitic flatworms. International Fournal for Parasitology 32, 329-342.

Sukhdeo, M. V. K. and Sukhdeo, S. C. (2004).

Trematode behaviours and the perceptual worlds of parasites. Canadian Fournal of Zoology 82, 292-315.

Tan, D.-X., Manchester, L. C., Hardeland, R., LopezBurillo, S., Mayo, J. C., Sainz, R. M. and Reiter, R. J. (2003). Melatonin: a hormone, a tissue factor, an autocoid, a paracoid, and an antioxidant vitamin. Fournal of Pineal Research 34, 75-78.

White, S. K., Secombes, C. J. and Chappell, L. H. (1991). Studies on the infectivity of Diplostomum spathaceum in rainbow trout (Oncorhynchus mykiss). Fournal of Helminthology 65, 169-178.

Whitehead, D. L. (1978). Application of a rapid method for determining glycosaminoglycans in mucus secreted by an aquatic pulmonate Biomphalaria glabrata.

Comparative Biochemistry and Physiology 59A, 27-30.

Zaunreiter, M., Brandstätter, R. and Goldschmid, A. (1998). Evidence for an endogenous clock in the retina of rainbow trout: I. Retinomotor movements, dopamine and melatonin. NeuroReport 9, 1205-1209. 